\title{
Turning T cells on: epigenetically enhanced expression of effector T-cell costimulatory molecules on irradiated human tumor cells
}

\author{
Anita Kumari, Ercan Cacan, Susanna F Greer and Charlie Garnett-Benson*
}

\begin{abstract}
Background: Sub-lethal doses of radiation can alter the phenotype of target tissue by modulating gene expression and making tumor cells more susceptible to T-cell-mediated immune attack. We have previously shown that sublethal tumor cell irradiation enhances killing of colorectal carcinoma cells by tumor-specific cytotoxic $T$ cells by unknown mechanisms. Recent data from our lab indicates that irradiation of tumor cells results in the upregulation of OX40L and 41BBL, and that T cells incubated with irradiated tumor cells displayed improved CTL survival, activation and effector activity. The objective of this current study was to determine the mechanism of enhanced OX40L and 41BBL expression in human colorectal tumor cells.
\end{abstract}

Methods: Two colorectal carcinoma cell lines, HCT116 and SW620, were examined for changes in the expression of $41 \mathrm{BBL}$ and OX40L in response to inhibition of histone deacetylases (using TSA) and DNA methyltransferases (using 5-Aza-2'-deoxycytidine) to evaluate if epigenetic mechanisms of gene expression can modulate these genes. Tumor cells were treated with radiation, TSA, or 5-Aza-dC, and subsequently evaluated for changes in gene expression using RT-qPCR and flow cytometry. Moreover, we assessed levels of histone acetylation at the 41BBL promoter using chromatin immunoprecipitation assays in irradiated HCT116 cells.

Results: Our data indicate that expression of 41BBL and OX40L can indeed be epigenetically regulated, as inhibition of histone deacetylases and of DNA methyltransferases results in increased OX40L and 41BBL mRNA and protein expression. Treatment of tumor cells with TSA enhanced the expression of these genes more than treatment with 5-Aza-dC, and co-incubation of T cells with TSA-treated tumor cells enhanced T-cell survival and activation, similar to radiation. Furthermore, chromatin immunoprecipitation experiments revealed significantly increased histone $\mathrm{H} 3$ acetylation of 41BBL promoters specifically following irradiation.

Conclusions: Full understanding of specific mechanisms of immunogenic modulation (altered expression of immune relevant genes) of irradiated tumor cells will be required to determine how to best utilize radiation as a tool to enhance cancer immunotherapy approaches. Overall, our results suggest that radiation can be used to make human tumors more immunogenic through epigenetic modulation of genes stimulatory to effector T-cells.

Keywords: External beam radiation, Immunogenic modulation, CTLS, Epigenetic, Effector co-stimulation

\footnotetext{
* Correspondence: cgarnettbenson@gsu.edu

Department of Biology, Center for Inflammation, Infection and Immunity,

Georgia State University, 161 Jesse Hill Jr. Dr, Atlanta, GA, USA
} 


\section{Background}

Previous reports by us and others demonstrate that sublethal doses of radiation alter the expression of genes within tumor cells [1-3]. Furthermore, it has been directly demonstrated that tumor irradiation, as well as treatment with some chemotherapy drugs, results in increased susceptibility to killing of tumor cells by cytotoxic $\mathrm{T}$ cells (CTLs) [1,4,5]. Notably, many genes that are important for T-cell anti-tumor effector activity are up-regulated following treatment with sub-lethal doses of radiation [2,4,6]. However, the mechanisms of radiation-mediated changes in the expression of such immune stimulatory genes are poorly understood.

It is clear that human cells respond to DNA-damage from ionizing radiation (IR) by inducing the expression of a number of genes at the transcriptional level $[4,7,8]$. Induction of altered gene expression can be due to direct cellular radiation effects or to radiation-induced changes in cellular milieu. Direct cellular effects appear to be regulated through parallel signaling pathways that originate from the nucleus following DNA damage, as well as signaling pathways that originate in the cytoplasm via reactive oxygen species production [7,9]. These pathways induce NF-kB activation and nuclear translocation $[10,11]$. As would be expected, DNA damage by IR can induce cellular stress responses, which result in activation of DNA damage repair pathways and apoptotic pathways [6,12]. Interestingly, regulation of the expression of a variety of genes, not related to known or typical DNA repair or apoptotic pathways, also occurs $[2,13,14]$. Indeed, we previously examined 23 human carcinoma cell lines for their phenotypic response to sub-lethal doses of IR [4], and found that RT increased the expression of several genes commonly down-regulated by tumors to escape immune recognition and elimination [15-20], including Fas (CD95), Intercellular adhesion molecule-1 (ICAM-1/CD54), tumor associated antigens (TAA) and major histocompatibility (MHC)-Class I. Most recently we found that radiation enhances the expression of OX40 ligand (OX40L/TNFSF4/CD134L/ CD252) and 41BB ligand (41BBL/TNFSF9/CD137L), important co-stimulators of effector CTLs on tumor cells (submitted manuscript).

To elicit an effective immune response against tumors, $\mathrm{T}$ cells need to recognize tumor antigens presented by MHC in conjunction with appropriate co-stimulation $[21,22]$. In the absence of proper co-stimulation, these anti-tumor $\mathrm{T}$ cells become anergic. Proteins such as 41BBL and OX40L represent important co-stimulators of effector CTL activity [23-26], and we have seen sublethal doses of radiation increase their expression in human tumor cells; however, the mechanisms regulating radiation-enhanced modulation of the expression of these two genes remain unclear. OX40 (TNFRSF4/
CD134) was originally characterized as a transiently expressed co-stimulatory molecule regulating $\mathrm{CD} 4$ and CD8 immunity [27], and signaling through OX40 promotes T-cell survival and expansion [28]. 41BBL costimulation of 41BB (TNFRSF9/CD137) on tumorspecific $\mathrm{T}$ cells is important for $\mathrm{T}$-cell proliferation [29,30], cytokine production, and activation [31]. Engagement of OX40 and 41BB by agonist antibodies increases immunity against tumors, resulting in longterm survival [32] in a number of murine tumor models $[33,34]$. Recent evidence indicates that expression of 41BBL is transcriptionally activated by HDAC inhibitors in leukemia cell lines [35], and that HDAC11 plays an essential role in regulating OX40L expression [36]. Interestingly, radiation has been shown to inhibit the expression of HDAC1 and HDAC2 [37], and we have seen enhanced cytolysis by T-cells following tumor irradiation. Thus, epigenetic mechanisms may be at work during radiation-enhanced susceptibility to T-cell killing.

Epigenetic changes such as histone modifications and DNA methylation play important roles in regulating gene expression. DNA methyltransferase enzyme (DNM T1) adds methyl group to cytosine residues [38]. DNA hypermethylation of $\mathrm{CPG}$ dinucleotides accumulates in promoter regions of genes and contributes to their loss through epigenetic silencing. Promoter hypermethylation and genome-wide hypomethylation alters genes expression in colorectal cancer [39]. It has been found that genes having hypermethylation also exhibit altered acetylation and methylation of histones [40]. Histone acetylation via histone acetyltransferases (HATs) is another major epigenetic mechanism controlling gene expression [41-43]. Gains in histone acetylation neutralize the positive charge on lysine residues and contribute to disrupted nucleosome structure, allowing unfolding of DNA, increased transcription factor access and enhanced gene expression [44-46]. HDACs remove acetyl groups from histones and return DNA to a less accessible conformation, thereby decreasing transcription [47-49]. Alterations in HAT and HDAC activity have been identified in many human cancers [50,51]. HDAC inhibitors (HDACi) therefore promote hyperacetylation of histones, which in turn leads to chromatin relaxation and selective expression of genes.

The roles of DNA methylation and histone acetylation in the expression of OX40L and 41BBL in response to radiation have not been investigated. Hence, we designed the present study to test the hypothesis that irradiation leads to increased expression of OX40L and 41BBL in colorectal tumor cells via epigenetic regulation. We measured the expression of effector CTL co-stimulatory molecules OX40L and 41BBL on human colorectal tumor cells lines after treatment with trichostatin (TSA) and 5-Aza-2'-deoxycytidine (5-Aza-dC). Ours is the first 
study to report that a) OX40L and 41BBL expression increases in CRC cells when DNMTs are inhibited, $b$ ) expression of OX40L and 41BBL increases in human CRC cells when HDACs are inhibited, $c$ ) HDAC inhibition in CRC cells can increase the activation and survival of $\mathrm{T}$ cells, and $d$ ) radiation treatment of tumor cells results in epigenetic modification of the histones in the promoter of the costimulatory gene 41BBL. The use of ionizing radiation to specifically enhance cancer immunotherapy (CIT) strategies through epigenetic modulation of genes stimulatory to CTLs will have a broad impact on cancer therapy approaches and will extend the use of radiation into new directions.

\section{Methods}

\section{Cell lines}

Human colorectal carcinoma cell lines HCT116 cells were obtained from the laboratory of tumor immunology and biology, NCI, NIH. The cell line SW620 was kindly provided by Zhi-Ren Liu [52] from Georgia State University, Department of Biology. All cells were cultured as recommended by ATCC and tested periodically to ensure absence of Mycoplasma. Cells were incubated at $37^{\circ} \mathrm{C}$ incubator with $5 \% \mathrm{CO}_{2}$.

\section{Reagents}

5-Aza-2'-deoxycytidine (5-Aza-dC) and Trichostatin A (TSA) were purchased from Sigma-Aldrich (St. Louis, MO). Antibodies recognizing histone $\mathrm{H} 3$ and acetylated histone $\mathrm{H} 3$ were from Millipore (Lake Placid, NY). Cell viability following treatment was determined using Trypan blue dye exclusion on a Countess automated cell counter (Life Technologies).

\section{Irradiation}

A RS-2000 biological X-ray irradiator (Rad source technology, Suwanee, GA) was used to irradiate tumor cells. Cells were irradiated at a dose rate of $2 \mathrm{~Gy} / \mathrm{min}$ by setting irradiator voltage and current at $160 \mathrm{kV}$ and $25 \mathrm{~mA}$, respectively. Cells were maintained in suspension and kept on ice during irradiation. Immediately after irradiation, the culture media was replaced with the fresh media.

\section{Quantitative real time PCR}

Cells were plated and treated with 5AZA-dC (20 uM), TSA or 10Gy radiation. Untreated control cells were cultured with the equivalent amount of DMSO present in drug treated samples. Adherent and viable cells were collected and RNA was extracted from tumor cells using RNeasy mini kit (Qiagen Inc. Valencia, CA) according to manufacturer's instructions. Purified RNA was DNasetreated by Rnase-free DNase (Qiagen Inc. Valencia, CA) following manufacturer's instructions. Expression of
OX40L and 41BBL mRNA was determined using real time RT-PCR. cDNA was synthesized using $500 \mathrm{ng}$ of mRNA. Amplification of cDNA was done using Dynamo cDNA synthesis kit (Finnzymes. Vantaa, Finland). Quantitative RT-PCR was conducted using TaqMan gene expression assay (Applied Biosystems; OX40L; Hs00967195, 41BBL; Hs00169409, and HPRT; Hs99999909) according to manufacturer's protocol. PCR thermal cycling condition was $50^{\circ} \mathrm{C}$ for $2 \mathrm{~min}, 95^{\circ} \mathrm{C}$ for $10 \mathrm{~min}, 40$ cycles of $95^{\circ} \mathrm{C}$ for 15 sec and $60^{\circ} \mathrm{C}$ for $1 \mathrm{~min}$ in a total volume of $20 \mu \mathrm{l} /$ reaction. Data were collected using a 7500 Real Time PCR System. All samples were run in duplicate. Hypoxanthine phosphoribosyltransferase (HPRT) was used as an endogenous house-keeping control gene and samples were normalized to expression of this gene, which was unchanged by treatment. Data were analyzed using the comparative Ct method [53].

\section{Flow cytometry}

Cells were stained with primary labeled mAb CD137L (41BBL)-PE, and CD252 (OX40L)-PE purchased from BioLegend (San Diego, CA). Surface staining was done in cell staining buffer for $30 \mathrm{~min}$ on ice. Flow cytometry data were acquired on BD Fortessa and analyzed with FlowJo software (TreeStar, version 9.6). Isotype control was kept less than 5\% in all the samples. Expression was considered increased if the absolute percent positive population increased by $10 \%$ or greater.

\section{Chromatin Immunoprecipitation (ChIP) Assay}

ChIP assays were performed as previously described [54]. Briefly, $48 \mathrm{~h}$ after irradiation (10Gy) and TSA (500 nM) treatment cells were seeded at a density of $2.0 \times 10^{6}$ and crosslinked with $1 \%$ formaldehyde. The crosslinking reaction was stopped by the addition of $0.125 \mathrm{M}$ glycine. Cell nuclei were isolated and concentrated by lysing in SDS lysis buffer (1\% SDS, $10 \mathrm{mM}$ EDTA, $50 \mathrm{mM}$ Tris $\mathrm{pH}$ 8.0, plus protease inhibitors) on ice followed by flash freezing in liquid nitrogen. Cell nuclei were sonicated using a Bioruptor to generate an average of $500 \mathrm{bp}$ of sheared DNA; DNA shearing was confirmed by subjecting lysates to agarose gel electrophoresis. Sonicated lysates were then precleared with salmon-sperm/agarose beads (Upstate) and $5 \%$ of the total lysate was stored as input for normalization. Half of the remaining lysate was immunoprecipitated with control antibody, and the other half was immunoprecipitated with $5 \mu \mathrm{g}$ of indicated antibody overnight at $4^{\circ} \mathrm{C}$. Following an additional two hour immunoprecipitation with salmon-sperm/agarose beads, all samples were washed with each of the following buffers: low salt buffer $(0.1 \%$ SDS, $1 \%$ Triton X-100, 2 mM EDTA, $20 \mathrm{mM}$ Tris $\mathrm{pH} 8.0,150 \mathrm{mM} \mathrm{NaCl})$, high salt buffer $(0.1 \%$ SDS, 1\% Triton X-100, 2 mM EDTA, 20 mM Tris pH 8.0, $500 \mathrm{mM} \mathrm{NaCl})$, LiCl buffer (0.25 M LiCl, 1\% NP40, 1\% 
DOC, $1 \mathrm{mM}$ EDTA, $10 \mathrm{mM}$ Tris $\mathrm{pH}$ 8.0), and 1xTE buffer. DNA was eluted with SDS elution buffer (1\% SDS, 0.1 $\mathrm{M} \mathrm{NaHCO}$ ) and then cross-links were reversed overnight with $5 \mathrm{M} \mathrm{NaCl}$ at $65^{\circ} \mathrm{C}$ and immunoprecipitated DNA was isolated using phenol:chloroform:isopropanol mix (Invitrogen) as per the manufacturer's instructions. Isolated DNA was quantified by real time PCR on an ABI prism 7900 (Applied Biosystems, Foster City, CA) using the following primers and probe for 4-1BBL: forward, 5'GCA CGC ATA GAC ATA AAT TGG C-3', reverse, 5'TCT GTG TCT CCC CGT TAA C -3' and probe, 5'-TCC ACC CAC TGC AGA GGC AAT CAA-3'; for GAPDH: forward, 5'-AAT GAA TGG GCA GCC GTT A-3', reverse, 5'-TAG CCT CGC TCC ACC TGA CT-3' and probe, 5'CCT GCC GGT GAC TAA CCC TGC GCT CCT-3'; and for CIITA: forward, 5'-CAG TTG GGA TGC CAC TTC TGA-3', reverse, 5'- TGG AGC AAC CAA GCA CCT ACT-3' and probe, 5'-AAG CAC GTG GTG GC-3'. Values generated from real time PCR reactions were calculated based on standard curves generated, were run in triplicate reactions and were analyzed using the SDS 2.0 program.

\section{Generation TAA-specific cytotoxic T-lymphocytes}

$\mathrm{PBMCs}$ from HLA-A2+ donors were purchased from Hemacare (Van Nuys, CA) for the generation of antigen specific CTLs as described elsewhere [4,55,56]. These leukapheresis samples, derived from HLA-A2+ patients, were obtained from Hemacare with appropriate informed consent. The use of these de-identified and commercially purchased tissues is under a human investigation protocol approved by the GSU IRB (exempt approval \#H13305). Briefly, PMBCs were allowed to adhere to T150 flask for $2 \mathrm{hr}$ in AIM-V media. After $2 \mathrm{hr}$, nonadherent cells were removed for lymphocyte isolation. Adherent cells were cultured for seven days in the presence of $100 \mathrm{ng} / \mathrm{ml}$ of human granulocyte colony stimulating factor (GM-CSF) and $20 \mathrm{ng} / \mathrm{ml}$ of IL-4. (Miltenyi Biotec, Inc. Auburn, CA) in AIM-V media and $500 \mathrm{ng} / \mathrm{ml} \mathrm{CD40L}$ (Millipore corporation, Temecula, CA) was added on day five to mature the DCs. On day seven DCs were collected and pulsed with $40 \mu \mathrm{g} / \mathrm{mL}$ of HLA-A2 binding CEA peptide (YLSGANLNL (CAP-1; [56],) peptide for $4 \mathrm{hr}$ in a $37^{\circ} \mathrm{C} 5 \% \mathrm{CO}_{2}$ incubator. Unused DCs were frozen and stored in liquid nitrogen for subsequent restimulations. DCs loaded with peptide were subsequently irradiated with 50Gy. Immunomagnetic beads (Miltenyi Biotec Inc. Auburn, CA) were used to isolate CD8+ T cells from the non-adherent cells, following manufacturer instructions. Subsequently, isolated CD8 + T cells were co-cultured with peptide pulsed DCs. IL-7 (Millipore, Temecula, CA) at $10 \mathrm{ng} / \mathrm{ml}$ and IL2 (Millipore, Temecula, CA) at $30 \mathrm{U} / \mathrm{ml}$ were added to each well on the first and third day, respectively. T-cells were restimulated in this manner weekly using mature autologous DCs. Restimulated T cells were isolated over ficoll on day seven of culture, and used in a T-cell activation and survival assays.

\section{T-cell activation and survival assay}

$1 \times 10^{3}$ colorectal tumor cells were irradiated or treated with TSA and plated in 96-well plate for $48 \mathrm{hr} .1 \times 10^{4}$ human CEA specific CD8+ T cells were subsequently added and co-cultured with the colorectal tumor cells for $48 \mathrm{hr}$. The percent of CD8+ T cells expressing CD69 or CD25 was measured by flow-cytometry. In parallel experiments, 7AAD was used to measure T-cell death. Flow cytometry data were acquired on BD Fortessa and analyzed with FlowJo software (TreeStar, version 9.6). The live cells population was gated on the FSC and SSC scatter plots for analysis of surface proteins. No live cells gate was used for cell death analysis samples. T cell stimulation for $24 \mathrm{~h}$ using a $(1 \times)$ cocktail of PMA and ionomycin (eBioscience) was used as a positive control for activation of TAA-specific T-cells.

\section{Statistical analysis}

Statistical differences between groups were calculated using un-paired two-tailed student T-test and calculated at $95 \%$ confidence using Graphpad by Prism. P-values less that 0.05 were considered statistically significant.

\section{Results}

OX40L and 41BBL transcripts increase when DNMTs and HDACs are inhibited

Exposure of human carcinoma cell lines to sub-lethal radiation results in enhanced susceptibility to lysis by tumor specific cytotoxic $\mathrm{T}$ cells (CTLs) [4,5], and costimulatory proteins such as $41 \mathrm{BBL}$ and OX40L represent important regulators of effector CTL activity $[22,26]$. These ligands for OX40 (OX40L/CD134L) and 41BB (41BBL/CD137L) are normally expressed on antigen presenting cells and activated endothelial cells. However, we have recently demonstrated expression of both proteins on tumor cells following treatment with radiation (submitted manuscript). Others have reported that changes in DNA methylation can upregulate the expression of costimulatory proteins in human tumor cells $[57,58]$. The dynamics of the induction of DNA methylation in irradiated tissue is currently unknown, and the role of methylation in expression of co-stimulatory molecules in response to radiation has not been investigated. We began our investigation by treating cells with 5 -Aza-2'deoxycytidine (5-Aza-dC) to inhibit DNA methylation in order to determine if this would alter expression of 41BBL or OX40L in human CRC cells. 5-Aza-dC is a DNA methyltransferase inhibitor (DNMTi) and is incorporated into DNA resulting in the rapid loss of DNA methyl transferase activity [59]. The human colorectal cell line 
HCT116 was treated with 5-Aza-dC for 48 or $72 \mathrm{hr}$, and OX40L and 41BBL mRNA was quantified. OX40L mRNA increased 1.4-fold (Figure 1A) and 41BBL mRNA increased approximately 2-fold (Figure 1B) at both 48 and $72 \mathrm{hr}$ post-treatment with 5-Aza-dC. OX40L mRNA increased over time in tumor cells treated with radiation, as there was a 2.3 -fold increase at $48 \mathrm{hr}$ and a 3.6-fold increase at $72 \mathrm{hr}$ (Figure 1A). Radiation induced a similar increase in 41BBL transcript levels. Interestingly, this temporal increase was not observed in tumor cells treated with 5-Aza-dC as relatively equal levels of both OX40L and $41 \mathrm{BBL}$ mRNA were detected after $48 \mathrm{hr}$ (gray bar) and $72 \mathrm{hr}$ (black bar) drug treatment. Moreover, the level of OX40L mRNA in cells treated 5-Aza-dC never exceeded those observed $72 \mathrm{~h}$ post-IR.
HDACs enzymes remove acetyl groups from histones and suppress gene transcription. Recent studies have shown that HDAC inhibitors also have immunemodulatory properties, such as increasing expression of HLA-DR, ICAM-1 and B7-2 in acute myeloid leukemia cell lines [60]. We next asked if inhibition of HDACs would result in increased expression of OX40L and $41 \mathrm{BBL}$ similar to the increase seen in radiation-treated cells. For these experiments we used Trichostatin A (TSA), an inhibitor of the class I and class II family of HDAC enzymes, and evaluated OX40L and 41BBL mRNA expression. HCT116 cells treated with TSA for $48 \mathrm{hr}$ (gray bar) contained more OX40L (Figure 1A) and $41 \mathrm{BBL}$ mRNA (Figure 1B) as compared to cells treated with 5 -Aza-dC for 48 or $72 \mathrm{hr}$. Messenger RNA levels

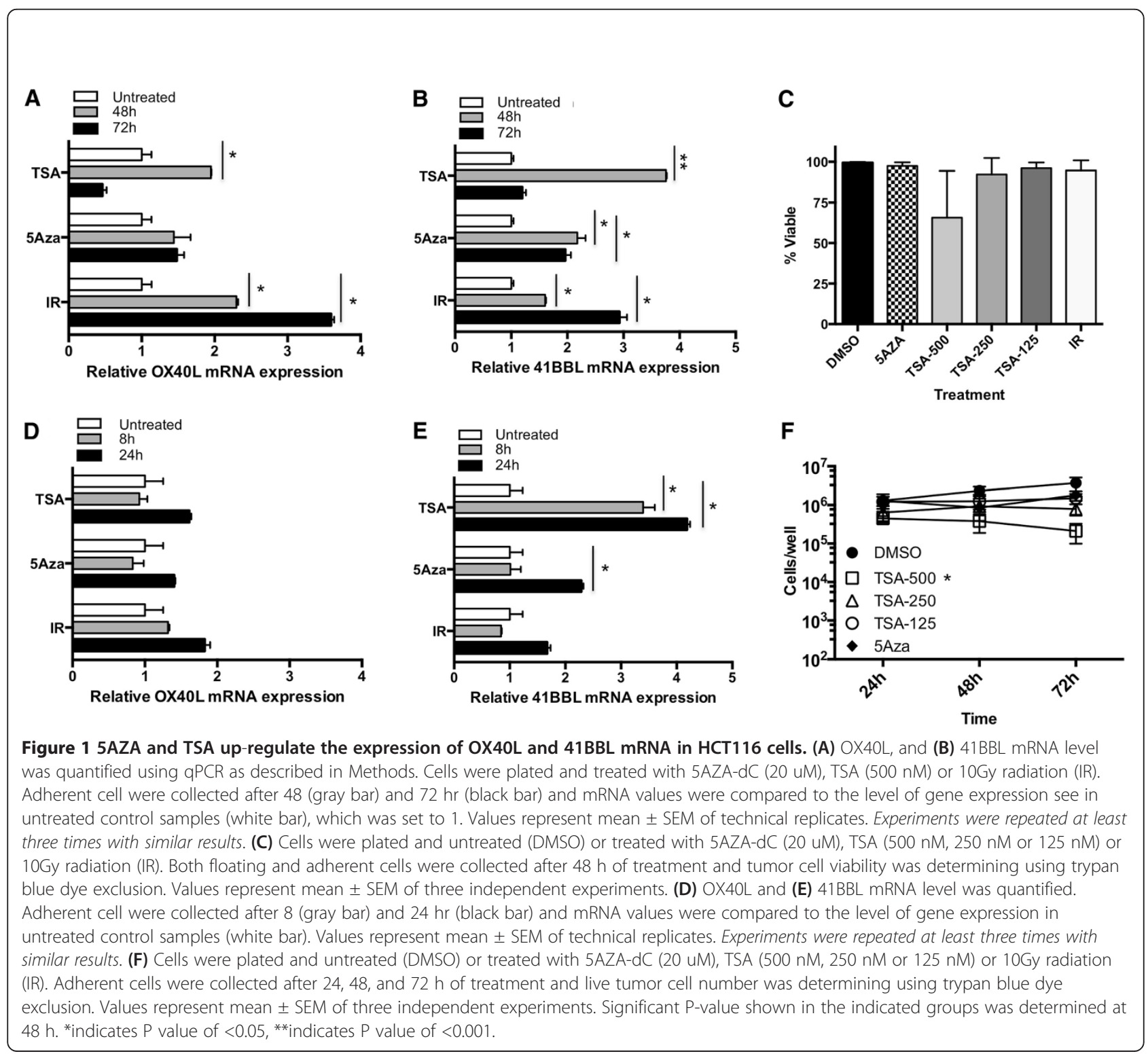


decreased after $72 \mathrm{hr}$ (gray bar) of TSA treatment; we note that these cells were sensitive to TSA toxicity and began dying after $48 \mathrm{hr}$ TSA treatment though this loss of viability did not reach significance (Figure $1 \mathrm{C}$ ). It is likely that mRNA expression at 48 and $72 \mathrm{~h}$ is not representative of early radiation events. As changes in promoter activation are often an early event we next evaluated cells at 8 and $24 \mathrm{~h}$ post-treatment. We found no significant increase in OX40L mRNA. Surprisingly, while radiation did not induce a significant increase in 41BBL RNA at 8 or $24 \mathrm{~h}$, TSA did at both time points (Figure 1). Indeed the increase in 41BBL mRNA at $24 \mathrm{~h}$ (4-fold) exceeded levels observed after $48 \mathrm{~h}$ treatment (Figure 1B). 5-Aza-dC began to increase $41 \mathrm{BBL}$ as early as $24 \mathrm{~h}$ after treatment by slightly greater that 2 -fold
(Figure 1E) and this increase was maintained during 48 and $72 \mathrm{~h}$ treatment (Figure $1 \mathrm{~B}$ ). However, both radiation and TSA induced more 41BBL mRNA than 5-Aza-dC at their respective times of maximum induction. Overall, inhibition of both HDACs and DNMTs increased the levels of OX40L and 41BBL mRNA in HCT116 cells.

To determine if epigenetic regulation of these genes was a common mechanism observable in carcinoma cells, we evaluated a second human CRC cell line, SW620. Again, SW620 cells were treated with 5-Aza-dC and TSA for 48 or $72 \mathrm{hr}$ and mRNA expression was measured by qRT-PCR. Overall, SW620 cells were more responsive to these treatments than HCT116 cells. 5Aza-dC upregulated the expression of OX40L by 5.3 fold (Figure $2 \mathrm{~A}$ ) and 41BBL by 3.5 fold (Figure $2 \mathrm{~B}$ ) in SW620
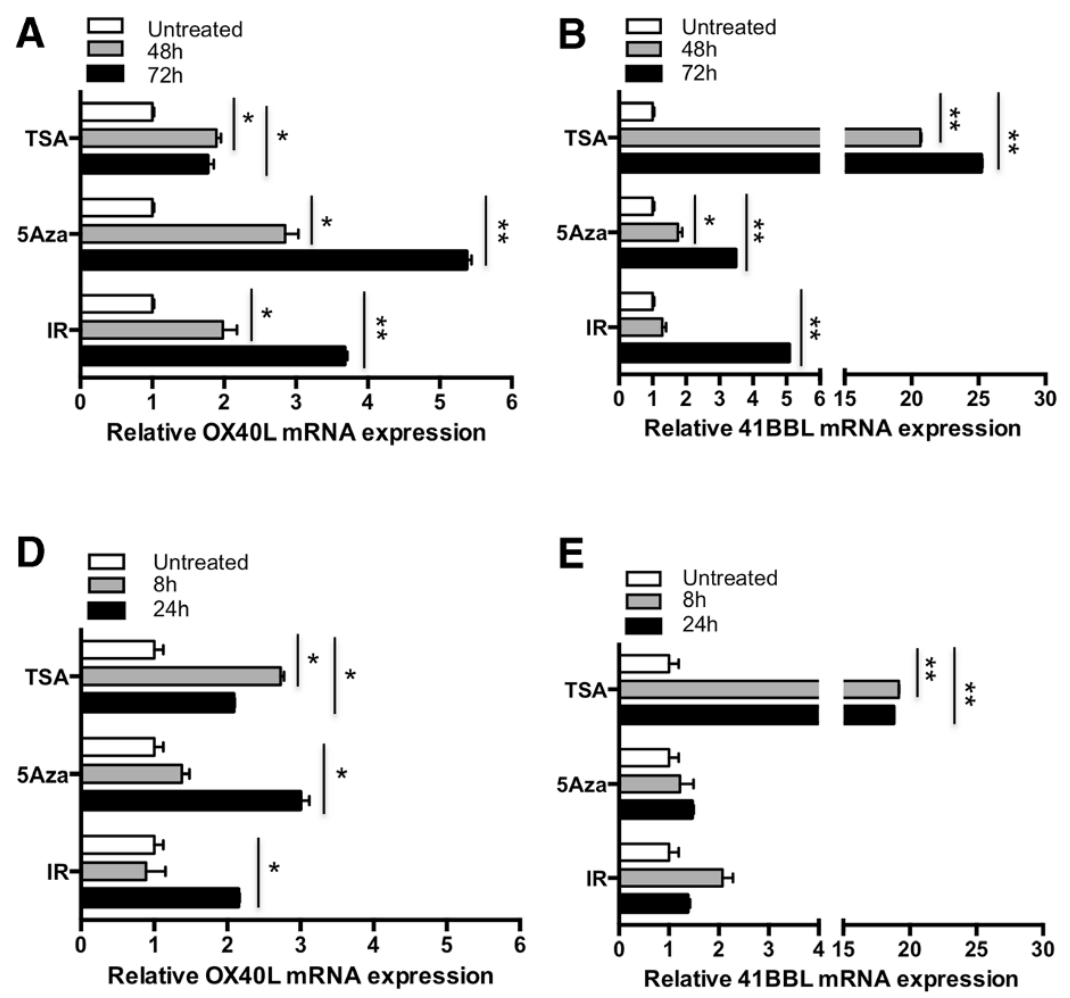

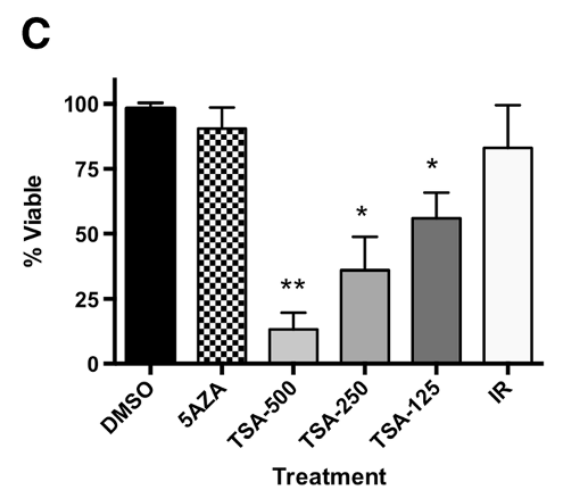

$\mathbf{F}$

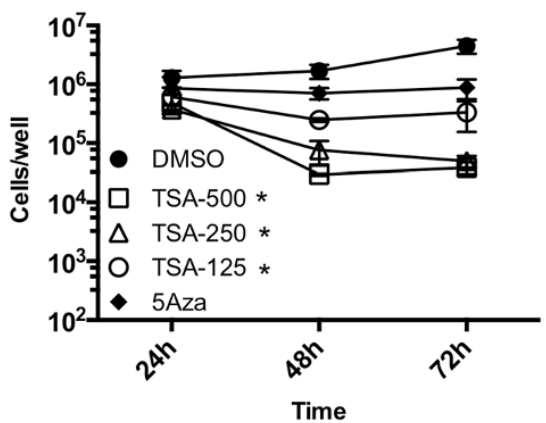

Figure 2 5AZA and TSA up-regulate the expression of OX40L and 41BBL mRNA in SW620 cells. (A) OX40L, and (B) 41BBL mRNA was quantified in SW620 cells using 9PCR. Cells were plated and treated with 5AZA-dC (20 uM), TSA (250 nM) or 10Gy radiation (IR). Adherent cell were collected after 48 (gray bar) and $72 \mathrm{hr}$ (black bar) and mRNA values were compared to the level of gene expression see in untreated control samples (white bar), which was set to 1. Values represent mean \pm SEM of technical replicates. Experiments were repeated at least three times with similar results. (C) Cells were plated and untreated (DMSO) or treated with 5AZA-dC (20 uM), TSA (500 nM, 250 nM or 125 nM) or 10Gy radiation (IR). Both floating and adherent cells were collected after $48 \mathrm{~h}$ of treatment and tumor cell viability was determining using trypan blue dye exclusion. Values represent mean \pm SEM of three independent experiments. (D) OX40L and (E) 41BBL mRNA level was quantified after 8 (gray bar) and $24 \mathrm{hr}$ (black bar) and compared to the level of gene expression in untreated control samples (white bar). Values represent mean \pm SEM of technical replicates. Experiments were repeated at least three times with similar results. (F) Cells were plated and left untreated (DMSO) or treated with 5AZA-dC (20 uM), TSA (500 nM, $250 \mathrm{nM}$ or $125 \mathrm{nM}$ ) or 10Gy radiation (IR). Adherent cells were collected after 24, 48, and $72 \mathrm{~h}$ of treatment and live tumor cell number was determining using trypan blue dye exclusion. Values represent mean \pm SEM of three independent experiments. Significant P-value shown in the indicated groups was determined at $48 \mathrm{~h}$. *indicates $\mathrm{P}$ value of $<0.05$, **indicates $\mathrm{P}$ value of $<0.001$. 
cells treated for $72 \mathrm{hr}$ (gray bar). HDAC inhibition by TSA robustly altered the expression of $41 \mathrm{BBL}$ mRNA resulting in a 25 -fold increase (Figure 2B), and again resulted in a more modest upregulation of OX40L by 1.8-fold in SW620 cells treated for $72 \mathrm{hr}$ (Figure 2A). Interestingly, these cells were more sensitive to TSA toxicity (Figure $2 \mathrm{C}$ ) and displayed significantly reduced cell numbers following 48 and $72 \mathrm{~h}$ treatment with TSA concentrations ranging from $500 \mathrm{nM}$ to $125 \mathrm{nM}$ (Figure 2F). Viable cell numbers decreased with TSA treatment time and dose (Figure 2C), however, RNA was isolated and analyzed from the adherent and viable cells remaining in the culture (Figure 2F) for our experiments (Figure 2A \& B). Moreover, we observed similar cell numbers remaining between the treatment groups after $24 \mathrm{~h}$ treatment with TSA and next evaluated changes in gene expression after 8 and $24 \mathrm{~h}$ treatment. Increased message for OX40L could be detected as early as $24 \mathrm{~h}$ in cells treated with radiation and 5-Aza-dC (Figure 2D) and was further increased after 48 and $72 \mathrm{~h}$ (Figure 2A). The largest increase in OX40L in response to TSA treatment in SW620 cells was detected following treatment for $8 \mathrm{~h}$ (2.7-fold) and was reduced slightly thereafter (2.1-fold). We also evaluated 41BBL expression after 8 and $24 \mathrm{~h}$ treatment. No significant change in $41 \mathrm{BBL}$ mRNA was observed at either of the earlier time points in cells treated with 5 -Aza-dC or radiation. In contrast, a significant and robust increase in 41BBL expression could be detected after both 8 and 24 hr TSA treatment (20-fold) (Figure 2E) that was further increased after 72 $\mathrm{hr}$ treatment (Figure 2B). We noted that the relative level of 41BBL mRNA in untreated control cells appeared to be higher than OX40L mRNA levels in both cell lines evaluated. Overall, the largest increases in mRNA were detected for 41BBL mRNA following treatment of CRC cells with TSA. We also found that TSA induced robust mRNA changes at earlier times of treatment $(8 \mathrm{~h}$ and $24 \mathrm{~h}$ ) while radiation-induced changes took longer and were greatest at later times of treatment ( $48 \mathrm{~h}$ and $72 \mathrm{~h}$ ).

Following tumor cell irradiation only adherent and proliferating cells were harvested for analysis. We have previously demonstrated that irradiated tumor cells continue to proliferate and remain viable using this method [6] (Figures 1C \& 2C). HCT116 cells appear to be less sensitive to TSA than SW620 cells as significantly reduced proliferation of treated HCT116 cells was detected only when the highest dose of TSA (500 nM) was used (Figure 1F). In contrast to TSA, there was very little impact of 5-Aza-dC on viability of tumor cells $48 \mathrm{~h}$ after treatment in either cell line (Figures $1 C \& 2 C$ ). Though cell numbers were slightly reduced following 5Aza-dC treatment of SW620 cells this was not significant (Figure 2F).
Surface expression of OX40L and 41BBL protein increases when DNMTs and HDACs are inhibited.

The largest increase in mRNA was detected in SW620 cells treated with 5-Aza-dC (OX40L, Figure $2 \mathrm{~A}$ ) or TSA $(41 \mathrm{BBL}$, Figure $2 \mathrm{~B})$, and we wanted to determine if increased protein expression also occurred. There was no significant difference in the total cell number (Figure 2F) or the viability (data not shown) of SW620 cells following $24 \mathrm{~h}$ hour treatment with $125 \mathrm{nM}$ TSA. As such, we evaluated surface expression of $41 \mathrm{BBL}$ protein by flow cytometry after $24 \mathrm{hr}$ treatment with either TSA $(125 \mathrm{nM})$ or 5-Aza-dC. Untreated SW620 cells expressed modest amounts of 41BBL on the surface (38.4\%), and as expected radiation increased the frequency to $60.4 \%$ (Figure 3A). Treatment with 5-Aza $-\mathrm{dC}$ had less of an impact on protein expression and $48 \%$ of cells expressed 41BBL after treatment with the drug (Figure 3C). In contrast, TSA had a much larger impact on protein expression and, similar to radiation-induced expression, $61 \%$ of TSA-treated SW620 cells expressed 41BBL (Figure 3D) (66\% in cells treated with $500 \mathrm{nM}$ ). Thus, relative changes in 41BBL protein expression (Figure 3A) and 41BBL mRNA quantities (Figure 2B) were similar in this cell line.

We next evaluated OX40L protein expression. SW620 tumor cells increased surface OX40L following exposure to $10 \mathrm{~Gy}$ of radiation (IR; 46.4\%), as compared to untreated cells (DMSO; 23.1\%) (Figure 3E). TSA increased protein expression of OX40L to a similar magnitude $(46.7 \%)$ as irradiated cells. Again, as seen with 41BBL, there was a smaller increase in surface OX40L detected (31.1\%) following treatment with 5-Aza-dC. This was surprisingly low given the 3 - to 5 -fold increase in OX40L mRNA seen in these cells upon 5-Aza-dC treatment (Figures 2A \& 2D). Thus, mRNA modulation of the two genes (Figure 2) was similar to protein changes by TSA and radiation (Figure 3), but not 5 -Aza-dC. Furthermore, the modulation of OX40L protein was less robust than that observed for 41BBL protein in SW620 cells (Figure 3B-3D \& 3F-3H).

Overall, our results show that TSA-treated cells demonstrated the largest increase in protein expression, and the increase was at least as good as that observed following treatment with radiation (Figure 3). As such, we focused our subsequent experiments on the impact of TSA HDAC inhibition on co-stimulatory molecule expression. Our data reveal increased expression of OX40L (53.2\%) $48 \mathrm{hr}$ after irradiation of HCT116 cells as compared to untreated (0Gy) cells (30.7\%) (Figure 4A-B \& 4E). Expression of OX40L is detected on the surface of 56.6\% TSA-treated HCT116 cells (Figure 4F) as compared to expression in control (DMSO) cells (38.2\%). 

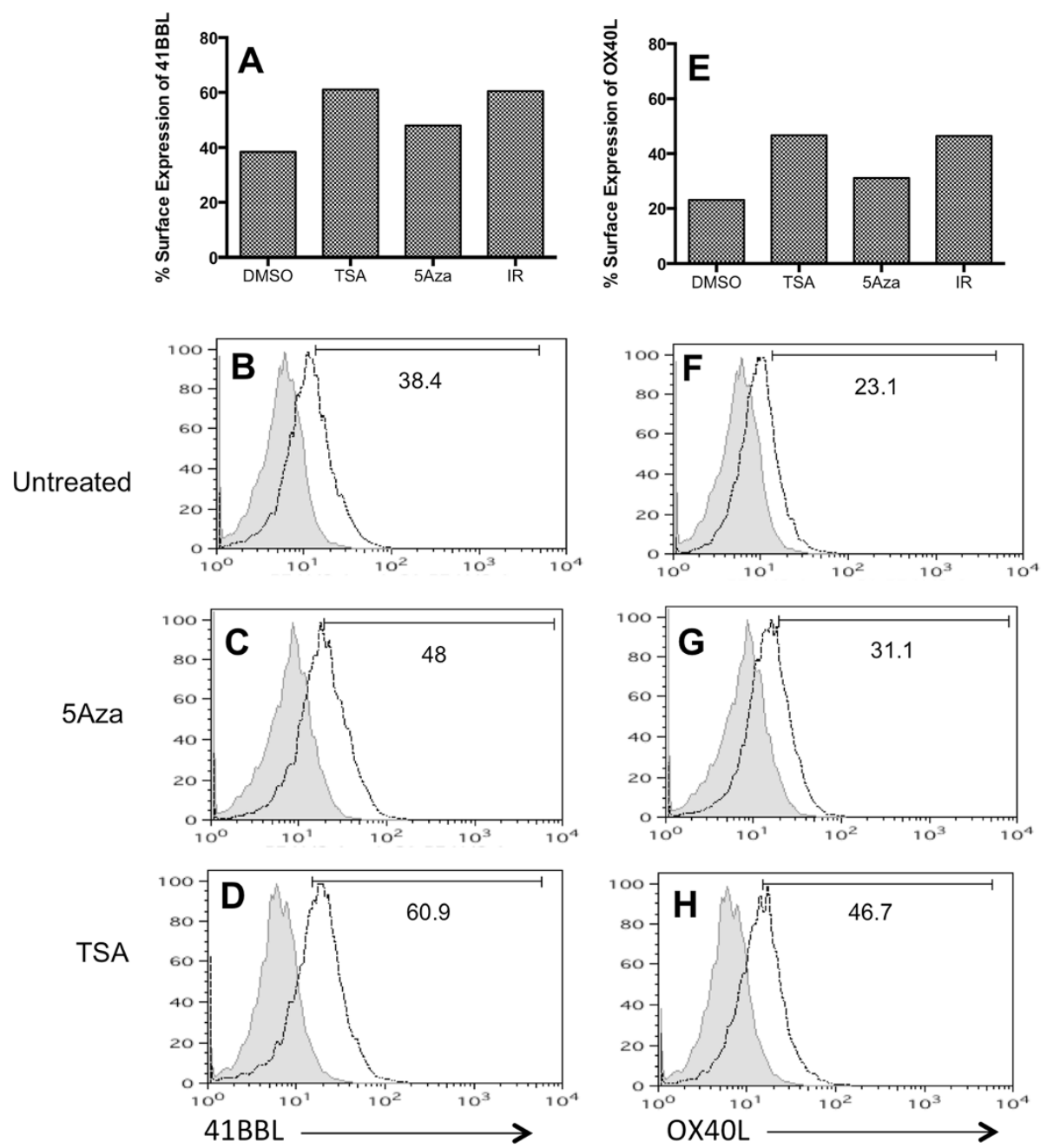

Figure 3 TSA and ionizing radiation increase surface expression of co-stimulatory molecules in SW620 cells more than 5AZA. (A-D) 41BBL, and (E-H) OX40L protein expression on the surface of SW620 cells was evaluated by flow cytometry. Cells were either untreated (DMSO), or treated with 5-Aza-dC (20 uM), TSA (125 nM) or 10Gy radiation (IR). Adherent cells were harvested $24 \mathrm{hr}$ post treatment, and stained with PE-labeled antibody to human OX40L or 41BBL. Isotype control stained cells were analyzed for each treatment group individually and set to $5 \%$ positive. Isotype control staining is shown as the gray filled histogram and protein specific staining is shown as black line histogram for the FACS plot data graphed in $\mathbf{A}$ and $\mathbf{E}$. Experiments were repeated twice with similar results.

Expression of 41BBL was also enhanced too much greater levels following treatment with both IR (43.6\% 10Gy) (Figure 4C-D \& 4E) and TSA (58.6\%-250 nM TSA versus 23\%-untreated) at $48 \mathrm{hr}$ (Figure 4G). The relative change in $41 \mathrm{BBL}$ surface expression compared to untreated cells was larger that the change in OX40L following TSA treatment in HCT116 cells (Figure 4H). Elevated levels of these co-stimulatory proteins could still be detected after 3- to 4-days of TSA treatment and radiationinduced changes where greater after $72 \mathrm{~h}$ (data not shown). Overall, both HCT116 and SW620 cells showed a more robust increase in expression of $41 \mathrm{BBL}$ as compared to OX40L protein expression upon TSA treatment.

\section{Radiation increases histone $\mathrm{H} 3$ acetylation at the 41BBL promoter}

Our data indicates that 41BBL and OX40L are epigenetically regulated and radiation increases expression of these genes in CRC cell lines. Histone acetylation facilitates transcription initiation by loosening interactions between the histones and DNA. Whereas, HDACs remove these acetyl groups from histones which reduces transcription. We observed that inhibition of HDACs by TSA increased 41BBL mRNA expression and surface protein levels in tumor cells. We observed that radiation increased 41BBL gene expression in a similar manner but was more robust at later times during treatment. As 

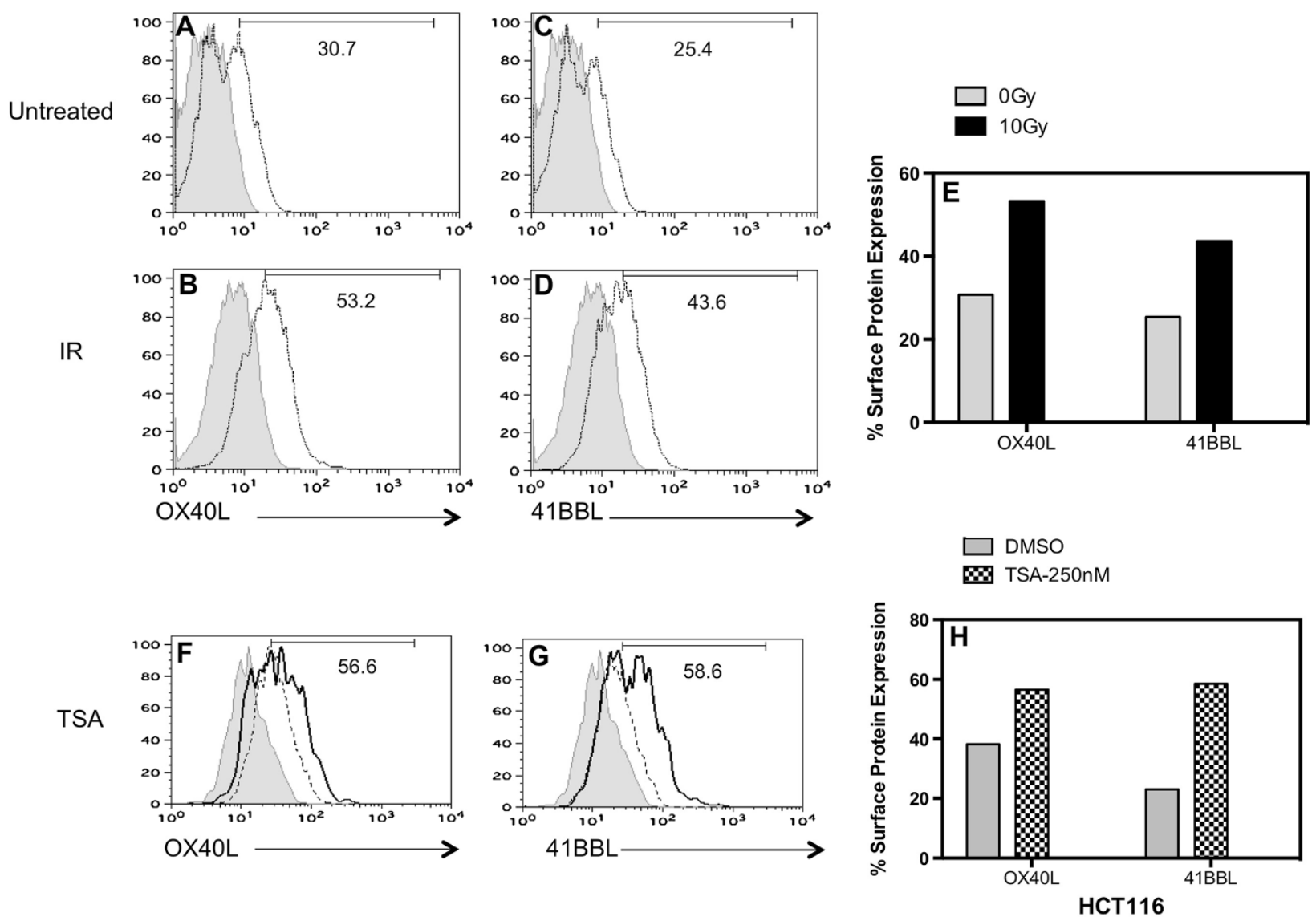

Figure 4 TSA and ionizing radiation treated HCT116 cells increase surface levels of 41BBL protein more than OX40L protein. (A, B and F) OX40L, and (C, D and G) 41BBL protein expression on the surface of HCT116 cells was evaluated by flow cytometry. (E) Cells were untreated (OGy) or treated with 10Gy radiation (IR). (H) In separate experiments HCT116 cells were untreated (DMSO) or treated with either TSA (250 nM). After $48 \mathrm{hr}$, cells were collected and stained with PE-labeled antibody to either OX40L and 41BBL. Control cell staining with a non-specific isotype control antibody was less than $5 \%$ positive. Isotype control staining is shown as the gray filled histogram and protein specific staining is shown as black line histogram for the FACS plot data graphed in $\mathbf{E}$ and $\mathbf{H}$. Dotted line histogram in F and $\mathrm{G}$ indicates specific protein expression in untreated cells. Values shown on histograms are for treated cells and untreated and treated values are displayed graphically in $\mathrm{H}$ for comparison. Experiments were repeated three times with similar results.

radiation has been reported to inhibit HDACs [37], we next wanted to determine if radiation could be increasing 41BBL expression by promoting increased promoter histone acetylation. To explore whether histone modifications are regulated in part by radiation, we assessed levels of histone acetylation at the 41BBL promoters using chromatin immunoprecipitation (ChIP) assays in both non-radiated and irradiated HCT116 cells. We evaluated promoter acetylation at $48 \mathrm{~h}$ post-IR when radiation-induced changes in mRNA levels were robust (Figure 1). TSA-treated HCT116 cells were used as a positive control for 41BBL promoter acetylation. As TSA inhibits HDAC activity, we expect to see robust increases in histone acetylation status following TSA treatment. As expected, Figure 5A shows increased acetylation at the 41BBL promoter following TSA treatment (gray bar) as compared to untreated control cells (white bar). Surprisingly, acetylated H3 histone levels were significantly higher at $41 \mathrm{BBL}$ promoters in irradiated cells (black bar). In contrast, similar levels of acetylated histone $\mathrm{H} 3$ were associated with the GAPDH promoter in both untreated and irradiated HCT116 cells (Figure 5B). Moreover, total levels of histone H3 were similar at 41BBL and GAPDH promoters revealing that there was no global change in overall histone levels (data not shown). These data indicate that radiation increases $41 \mathrm{BBL}$ expression by increasing histone acetylation. To determine if radiation non-specifically increases histone acetylation levels at other genes, histone H3 ChIP assays were performed on the Class II 
Transactivator (CIITA) promoter IV. Histone H3 acetylation levels were similar for non-irradiated, irradiated and TSA treated cells at CIITA promoter IV (Figure 5C), which suggests gene-specificity for radiation-induced $41 \mathrm{BBL}$ promoter acetylation, likely via HDAC inhibition.

\section{Treatment of CRC cells with TSA enhances T-cell survival} and activation similar to co-incubation with irradiated

\section{tumor cells}

To investigate the impact of HDAC inhibition in tumor cells on T-cell survival, we measured T-cell death by 7AAD staining after $48 \mathrm{hr}$ co-incubation with tumor cells. $7 \mathrm{AAD}+$ staining determined cell death of $8.96 \%$ of CD8+ T cells incubated alone (Figure 6A). The frequency of dead CD8+ T cells increased to $24.8 \%$ following co-incubation with untreated SW620 cells (Figure 6B). Death of T-cells following interaction with tumor cells has been reported by others, and is thought to be caused by tumor expressed PDL1, FasL and/or activation induced cell death (AICD) [61-63]. Incubation of T-cells with SW620 cells, which had been treated with TSA for $48 \mathrm{hr}$, reduced the percentage of dead $\mathrm{T}$ cells to $17.6 \%$ (Figure 6D) similar to incubation with irradiated tumor cells (16.6\%). A reduction in T-cell death (18\%) was also observed when T-cells were co-incubated with TSA-treated HCT116 cells as compared to untreated tumor cells (26\%) (Figure 6E). These data indicate that HDAC inhibition by TSA treatment of tumor cells increases the survival of $\mathrm{CD}^{+} \mathrm{T}$ cells following co-incubation with tumor cells.

CD25 and CD69 are surface markers expressed on activated $T$ cells [64]. Data from our lab supports the hypothesis that changes in the expression of tumorexpressed 41BBL and OX40L contribute to increased killing of irradiated tumor cells by CTLs (submitted manuscript). We have also observed increased expression of

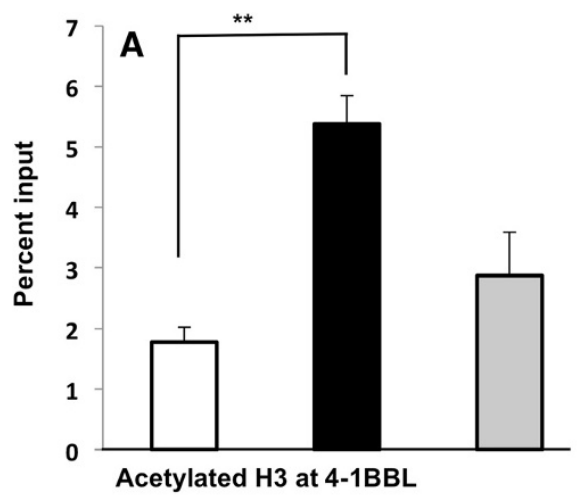

Non-irradiated

Irradiated

TSA-treated
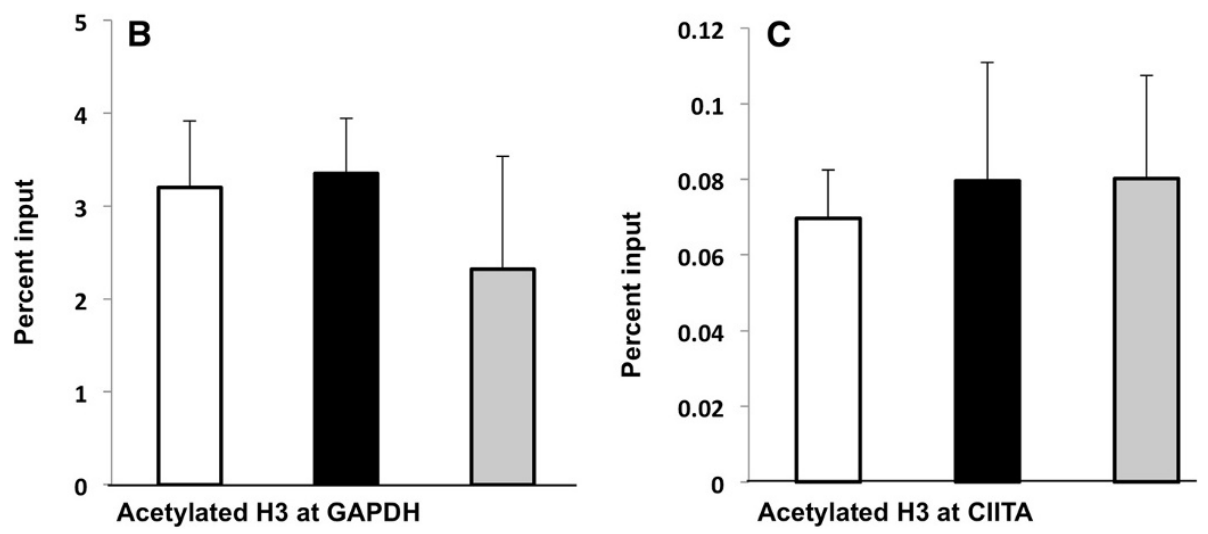

Figure 5 Histone acetylation at 41BBL promoters in non-radiated and irradiated cells. ChIP assays were carried out in non-irradiated, irradiated (10 Gy), and TSA-treated (500 nM) HCT116 cells. Following 48 h of TSA treatment, lysates were immunoprecipitated with control antibody or with anti-acetyl histone H3. Associated DNA was isolated and analyzed via real time PCR using primers spanning the 41BBL, GAPDH and CIITA promoters. Real-time PCR values were normalized to the total amount of promoter DNA added (input). Input values represent $5 \%$ of the total cell lysate. Values represent mean \pm SEM of three independent experiments. ${ }^{*} \mathrm{P}<0.005$. A. Global levels of Histone $\mathrm{H} 3$ acetylation associated with the 41BBL promoter. B. Global levels of Histone H3 acetylation associated with the GAPDH promoter. C. Global levels of acetylated Histone $\mathrm{H} 3$ associated with the CIITA promoter. 


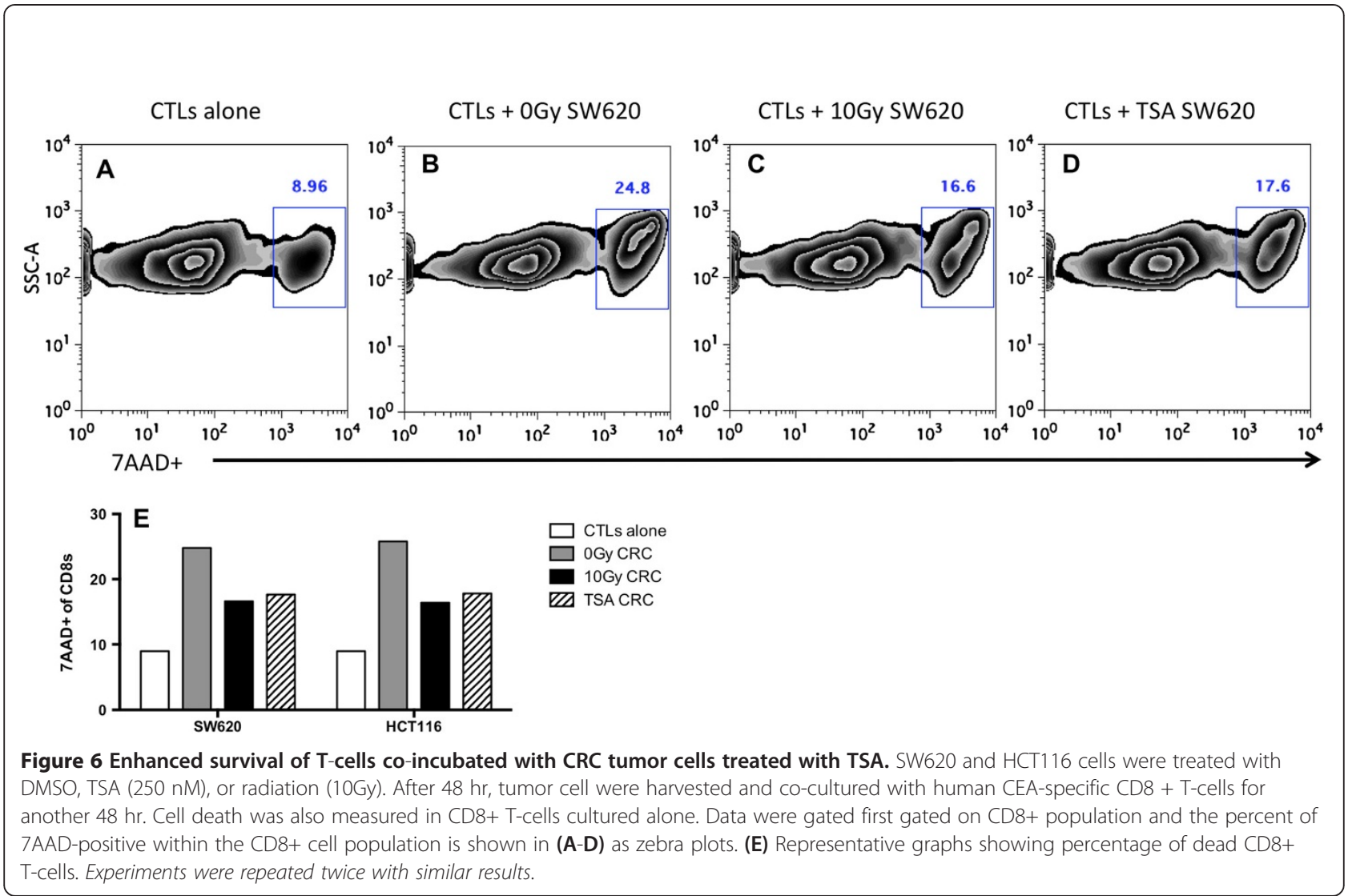

CD25 and CD69 on T cells following co-incubation with irradiated tumor cells compared to non-irradiated tumor cells. Lastly, we have observed increased viability of $\mathrm{T}$ cells cultured with irradiated tumor cells. We next determined if tumor cells treated with HDACi induced similar changes in $\mathrm{T}$ cell activation. Non-treated, irradiated or TSA treated tumor cells were co-cultured with $\mathrm{CD}^{+} \mathrm{T}$ cells, and after $48 \mathrm{hr}$ the expression of CD25 on T cells was measured by flow cytometry. We found that $29.5 \%$ of CD8+ T cells incubated with untreated tumor cells expressed CD25 (Figure 7A), and this frequency was reduced compared to activation of $\mathrm{T}$ cells incubated alone (34.1\%) (Figure 7D). This reduction is not surprising as reduced activity and activation of T-cells following interaction with tumor cells has been described by others [61-63]. The frequency of $\mathrm{CD}_{25}{ }^{+}$within the $\mathrm{CD}^{+} \mathrm{T}$ cell population increased following co-incubation with either radiation-treated (Figure 7B) or TSA-treated tumor cells to 35.3\% (Figure 7C). In fact, the frequency of activated $\mathrm{T}$ cells following coincubation with TSA-treated cells was equal to $\mathrm{T}$ cells not co-incubated with tumor cells (34.1\%). CD25 expression in T-cells activated with PMA and ionomycin are shown as a positive control (Figure 7E). We evaluated a second CRC cell line and found that TSA-treated HCT116 cells also increased the frequency of $\mathrm{CD} 8{ }^{+} \mathrm{CD} 25^{+}$cells to $41 \%$, as compared to the frequency activated in the presence of untreated HCT116 cells (36.6\%) (Figure 7F). Irradiated tumor cells also increased $\mathrm{CD} 25^{+}$expression to $36.4 \%$ and the dynamics of T-cell activated were similar in repeat experiments. We observed a similar increase in the frequency of $\mathrm{CD} 9^{+} \mathrm{T}$ cells following co-incubated with TSA-treated or irradiated tumor cells (data not shown). These data suggest that $\mathrm{T}$ cells exposed to TSA treated tumor cells have improved activation. As a component of the IL-2 receptor, CD25 it has been linked to increased survival in studies by others and thus could be a contributor to the increased survival we observe following TSA treatment (Figure 6).

\section{Discussion}

Modulation of costimulatory molecules such as OX40L and 41BBL appear to be particularly important for maintaining effective immune responses against selfantigens presented by tumor cells. Here, we report that costimulatory molecule promoter histones can be acetylated in colorectal tumors in response to sub-lethal radiation (Figure 5A). Most studies of radiation-induced gene expression have used large cytotoxic doses of radiation, and mechanisms of altered gene expression are much less explored in cells receiving low or sub-lethal doses of radiation. Results of this study suggest that radiation therapy may be useful to specifically modulate gene expression within tumor targets. This mechanism 
CTLs +: 0 Gy SW620

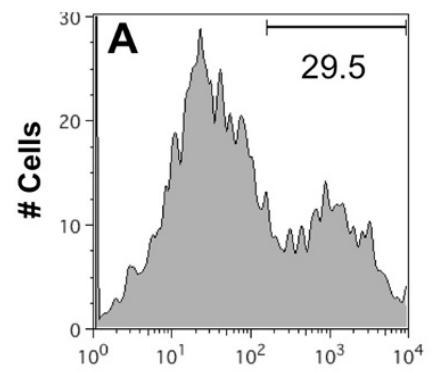

CD25-APC

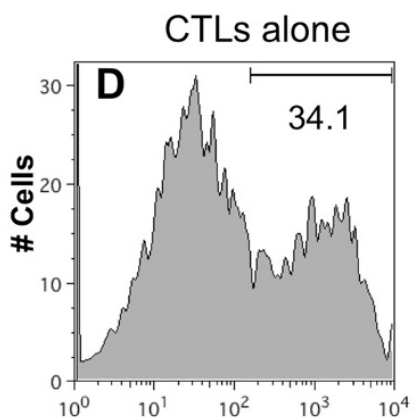

CD25-APC

10Gy SW620
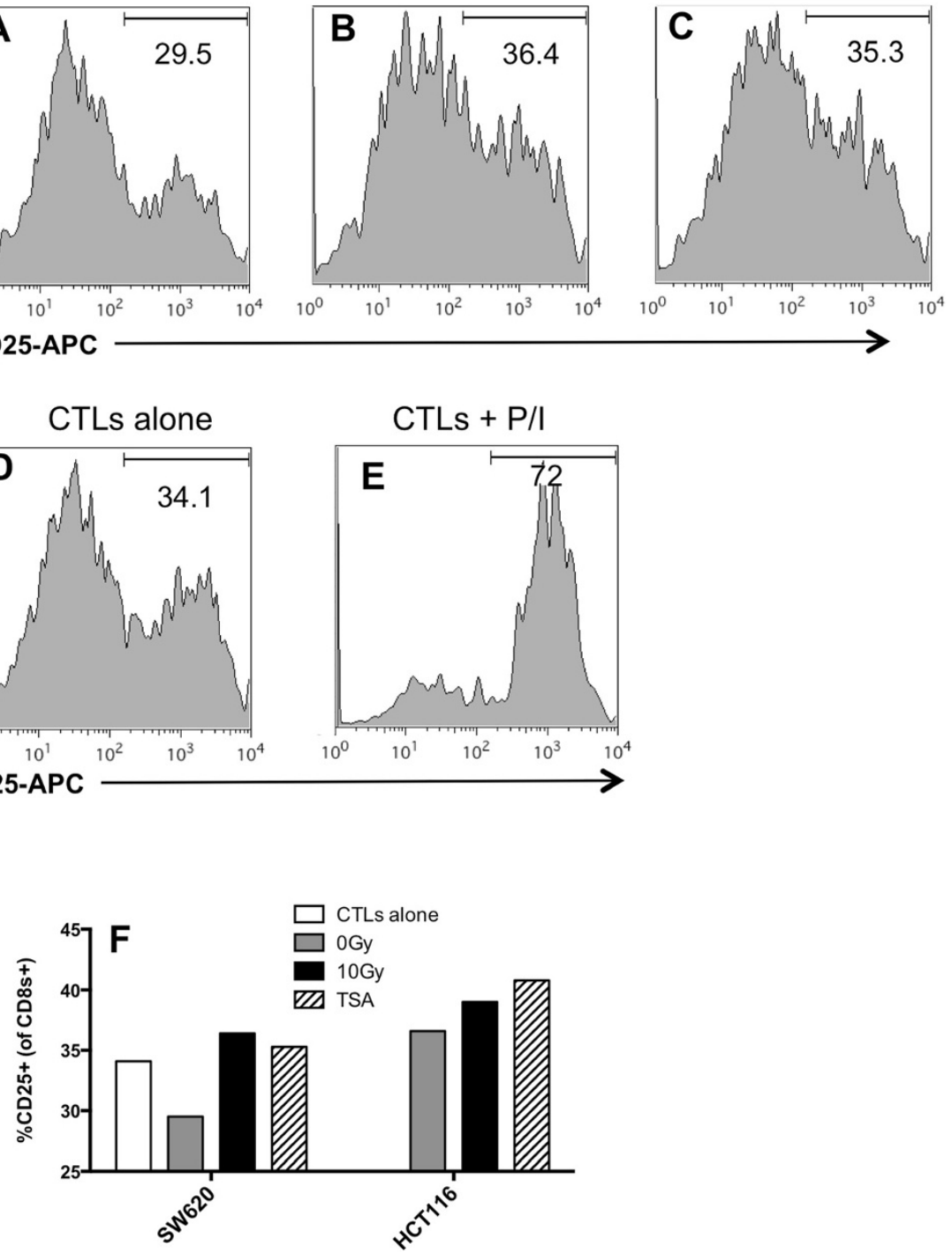

Figure 7 TSA-treated CRC tumor cells induce enhanced activation of CD8+ T-cells. SW620 cells were either (A) untreated, (B) irradiated or incubated with (C) 250 uM TSA for $48 \mathrm{hr}$ or as previously described. Tumor cells were subsequently co-cultured with human CEA-specific CD8 + T-cells for $48 \mathrm{hr}$ and the frequency of CD8 + CD25+ T-cells was measured by flow cytometry. T-cell activation was also measured in (D) CD8+ T-cells cultured alone or (E) activated with PMA and ionomycin (P/I) for $24 \mathrm{~h}$. Data were gated first gated on CD8+ population and the percent of CD25+ cells within the CD8+ cell population is shown in (A-E) as histogram plots. (F) a summary graph of results showing percentage of CD8 + T-cells expressing CD25 in both SW620 and HCT116 cells. Experiments were repeated twice with similar results.

would be useful against radioresistant cancer cells, and could occur even in the absence of immunogenic cell death (cell death that invokes enhanced antigen processing and presentation) [65]. Full understanding of specific mechanisms of immunogenic modulation (altered expression of immune relevant genes) [66] of irradiated tumor cells will be required to determine how to best utilize radiation as a "tool" to enhance cancer immunotherapy approaches.
Dramatic changes in DNA methylation are common in cancer, and manifest primarily as global DNA hypomethylation, paralleled by local hypermethylation at gene promoters resulting in loss of gene expression $[67,68]$. Tumor cells down-regulate the expression of many genes needed for induction of effective anti-tumor immune activity $[15,16,18,19]$, and DNA methylation may be one mechanism employed to accomplish this. Our studies reveal that inhibition of DNMT in tumor 
cells using 5-Aza-dC could induce mRNA expression of both OX40L and 41BBL on two different CRC cell lines (Figure $1 \& 2$ ). Although a greater than 5 -fold induction of mRNA was detected in SW620 cells treated with 5Aza-dC, we did not observe a robust increase in protein expression upon 5-Aza-dC treatment of these cells (Figure 3). These discordant results could simply be a result of the time of evaluation post-treatment. 41BBL mRNA was maximally increased $72 \mathrm{hr}$ post-treatment with 5-Aza-dC, while protein expression was evaluated after $24 \mathrm{~h}$ of treatment to keep cell death low at time of evaluation. Current studies are underway to determine if 5 -Aza-dC can indeed upregulate protein expression at later times post-treatment.

HDAC inhibition has been shown to be involved in modulating the expression of TNF family members $[69,70]$. In this study we extended analysis to other TNF family members and found that both $41 \mathrm{BBL}$ and OX40L expression could also be modulated by inhibition of HDACs. We found that the expression of both OX40L and $41 \mathrm{BBL}$ was increased on the surface of tumor cells treated with TSA for $24 \mathrm{hr}$ (Figure 3) or $48 \mathrm{hr}$ (Figure 4). Interestingly, the impact of HDAC inhibition by TSA on $41 \mathrm{BBL}$ protein expression was much more robust than changes observed in the expression of OX40L protein following TSA treatment. Studies are currently underway to evaluate changes in histone acetylation at the OX40L promoter to determine how acetylation is impacted by TSA inhibition of HDACs. We also observed increased expression of co-stimulatory proteins as long as four days after TSA-treatment and irradiation. While many of the cellular stress response genes are acute response genes whose expression is altered transiently, other genes remain altered for prolonged periods of time [71-73]. As such, altered gene expression following radiation treatment that is sustained is not unexpected.

The TNF family includes numerous costimulatory molecules known to play an important role in $\mathrm{CD}^{+} \mathrm{T}$ cell activation and survival. We found that inhibition of HDACs in tumor cells resulted in enhanced T-cell survival (Figure 6) and activation (Figure 7). To our knowledge this is the first study to explore the impact of radiation-induced epigenetic changes in tumor cells on the quality of anti-tumor CTLs. We are currently investigating if, by promoting T-cell survival and activation, the altered expression of these specific genes by HDACi enhances the tumor cells' susceptibility to T-cell-mediated immune attack in a manner similar to observations in irradiated tumor cells (submitted manuscript). Future studies seek to more fully investigate if increased signaling through CD25 is directly responsible for the increased survival of $\mathrm{T}$-cells by evaluating $\mathrm{T}$ cells after shorter periods of co-incubation as well as investing intracellular regulators of T-cell apoptosis.
HDACs enzymes reverse the activity of HATs by removing acetyl group and thus suppressing gene transcription. In several tumors, the expression of HATs is down-regulated, whereas HDACs is upregulated [74,75]. As previously mentioned, alteration of HAT and HDAC activity has been observed in tumor cell lines. HDACi induce a potent anticancer response by inhibiting HDACs [76,77]. HDACi have various biological effects, such as inhibition of cell cycle at G1/G2 phase, induction of differentiation and apoptosis of tumor cells [78-80]. Our results reveal that radiation treatment changes the epigenetic landscape of the 41BBL gene via an increase in histone acetylation, displaying a marked increase in $\mathrm{H} 3$ acetylation at this specific promoter, as compared to our positive control of cells treated with the HDACi, TSA. We also observed that TSA induced robust $41 \mathrm{BBL}$ mRNA changes at earlier times of treatment ( $8 \mathrm{~h}$ and $24 \mathrm{~h}$ ) while radiation-induced changes took longer and were greatest at later times of treatment (48 $\mathrm{h}$ and $72 \mathrm{~h}$ ). These data, in combination with increase promoter acetylation, suggest that radiation mediated effects take longer to modulate histone acetylation events than direct modulators such as TSA. This could be related to differences in modulation of HATs versus HDAC inhibitors. Current lab efforts are pursuing the mechanism for these epigenetic changes in primary carcinoma cells; specifically, does IR treatment change the activity of HATs, HDACs or both? If HDACs are involved, specific HDAC inhibitors will be utilized to identify which HDACs suppression(s) are vital for the upregulation of 41BBL expression. Also, how long can these epigenetic changes be maintained to promote increased effector T-cell function? Finally, we note that expression of OX40L and 41BBL varied with different concentrations of drug exposure. Our focus here is to describe a novel gene regulatory mechanism by epigenetic modification in response to irradiation. However, the application of clinically relevant doses of TSA and 5-Aza-dC, which might be combined with radiation, will also require a further investigation in a broad range of tumor cells.

\section{Conclusions}

The current study was meant to enhance our ability to design cancer immunotherapy (CIT) approaches in combination with RT. A better understanding of how IR modulates the expression of 41BBL and OX40L will allow improvement in our ability to use RT to specifically enhance CTL killing. Epigenetic mechanisms of gene expression could be an alternative therapeutic approach to enhancing these important T-cell signals. This approach is particularly relevant given the toxicities associated with using agonistic antibodies to $41 \mathrm{BB}$ and anti-OX40 antibodies in the clinic $[28,81]$. Alternate 
ways of triggering these signal pathways would be widely applicable in current CIT approaches. Furthermore, if radiation is shown to have a profound and consistent effect on immune stimulatory gene expression, this would provide support for using IR in conjunction with CIT strategies to specifically enhance such signals to T-cells arriving at tumor sites and optimize anti-tumor CTL responses.

\begin{abstract}
Abbreviations
5-Aza-dC: 5-Aza-2'-deoxycytidine; CEA: Carcinoembryonic antigen; CIT: Cancer immunotherapy; ChIP: Chromatin immunoprecipitation; CRC: Colorectal carcinoma; CTL: Cytotoxic T cells; DMSO: Dimethyl sulfoxide; DNMTs: DNA methyltransferases; HDACi: HDAC inhibitors; HDACs: Histone deacetylases; IR: Ionizing radiation; RT: Radiation therapy; TSA: Trichostatin A
\end{abstract}

\section{Competing interests}

The authors declare that they have no competing interests.

\section{Authors' contributions}

Conceived and designed the experiments: CGB and SFG. Performed the experiments: AK, EC and CGB. Analyzed the data: AK, EC and CGB. Contributed reagents/materials/analysis tools: CGB and SFG. Wrote the paper: CGB, AK, EC and SFG. All authors read and approved the final manuscript.

\section{Authors' information}

C. Garnett-Benson previously published under Garnett, C.T.

\section{Acknowledgement}

The authors would like to thank Melissa Heffner and Dr. Alex Spring for help in editing the manuscript. This research was supported by a Mentored Award Grant from Georgia State University.

Received: 23 April 2013 Accepted: 12 September 2013 Published: 23 September 2013

\section{References}

1. Chakraborty M, Abrams SI, Camphausen K, Liu K, Scott T, Coleman CN, Hodge JW: Irradiation of tumor cells up-regulates Fas and enhances CTL lytic activity and CTL adoptive immunotherapy. J Immunol 2003, 170:6338-6347.

2. Friedman EJ: Immune modulation by ionizing radiation and its implications for cancer immunotherapy. Curr Pharm Des 2002, 8:1765-1780.

3. Demaria S, Kawashima N, Yang AM, Devitt ML, Babb JS, Allison JP, Formenti SC: Immune-mediated inhibition of metastases after treatment with local radiation and CTLA-4 blockade in a mouse model of breast cancer. Clin Cancer Res 2005, 11:728-734.

4. Garnett CT, Palena C, Chakraborty M, Tsang KY, Schlom J, Hodge JW: Sublethal irradiation of human tumor cells modulates phenotype resulting in enhanced killing by cytotoxic T lymphocytes. Cancer Res 2004, 64:7985-7994.

5. Gelbard A, Garnett CT, Abrams SI, Patel V, Gutkind JS, Palena C, Tsang KY, Schlom J, Hodge JW: Combination chemotherapy and radiation of human squamous cell carcinoma of the head and neck augments CTL-mediated lysis. Clin Cancer Res 2006, 12:1897-1905.

6. Ifeadi V, Garnett-Benson C: Sub-lethal irradiation of human colorectal tumor cells imparts enhanced and sustained susceptibility to multiple death receptor signaling pathways. PLoS One 2012, 7:e31762.

7. Brzoska K, Szumiel I: Signalling loops and linear pathways: NF-kappaB activation in response to genotoxic stress. Mutagenesis 2009, 24:1-8.

8. Makinde AY, John-Aryankalayil M, Palayoor ST, Cerna D, Coleman CN: Radiation survivors: understanding and exploiting the phenotype following fractionated radiation therapy. Mol Cancer Res 2013, 11:5-12.

9. Janssens S, Tschopp J: Signals from within: the DNA-damage-induced NF-kappaB response. Cell Death Differ 2006, 13:773-784.

10. Li N, Karin M: lonizing radiation and short wavelength UV activate NF-kappaB through two distinct mechanisms. Proc Natl Acad Sci USA 1998, 95:13012-13017.
11. Schreck R, Albermann K, Baeuerle PA: Nuclear factor kappa B: an oxidative stress-responsive transcription factor of eukaryotic cells (a review). Free Radic Res Commun 1992, 17:221-237.

12. Amundson SA, Do KT, Fornace AJ Jr: Induction of stress genes by low doses of gamma rays. Radiat Res 1999, 152:225-231.

13. Gasser S, Raulet DH: The DNA damage response arouses the immune system. Cancer Res 2006, 66:3959-3962.

14. Sreekumar A, Nyati MK, Varambally S, Barrette TR, Ghosh D, Lawrence TS, Chinnaiyan AM: Profiling of cancer cells using protein microarrays: discovery of novel radiation-regulated proteins. Cancer Res 2001, 61:7585-7593.

15. Bubenik J: Tumour MHC class I downregulation and immunotherapy (Review). Oncol Rep 2003, 10:2005-2008.

16. French LE, Tschopp J: Defective death receptor signaling as a cause of tumor immune escape. Semin Cancer Biol 2002, 12:51-55.

17. Kojima H, Shinohara N, Hanaoka S, Someya-Shirota Y, Takagaki Y, Ohno H, Saito T, Katayama T, Yagita H, Okumura K, et al: Two distinct pathways of specific killing revealed by perforin mutant cytotoxic $T$ lymphocytes. Immunity 1994, 1:357-364.

18. Zamai L, Rana R, Mazzotti G, Centurione L, Di Pietro R, Vitale M: Lymphocyte binding to K562 cells: effect of target cell irradiation and correlation with ICAM-1 and LFA-3 expression. Eur J Histochem 1994, 38(Suppl 1):53-60.

19. Slavin-Chiorini DC, Catalfamo M, Kudo-Saito C, Hodge JW, Schlom J, Sabzevari $\mathrm{H}$ : Amplification of the lytic potential of effector/memory CD8+ cells by vector-based enhancement of ICAM-1 (CD54) in target cells: implications for intratumoral vaccine therapy. Cancer Gene Ther 2004, 11:665-680.

20. Modrak DE, Gold DV, Goldenberg DM, Blumenthal RD: Colonic tumor CEA, CSAp and MUC-1 expression following radioimmunotherapy or chemotherapy. Tumour Biol 2003, 24:32-39.

21. Jensen SM, Maston LD, Gough MJ, Ruby CE, Redmond WL, Crittenden M, Li $Y$, Puri S, Poehlein $\mathrm{CH}$, Morris $\mathrm{N}$, et al: Signaling through OX40 enhances antitumor immunity. Semin Oncol 2010, 37:524-532.

22. Kroczek RA, Mages HW, Hutloff A: Emerging paradigms of T-cell co-stimulation. Curr Opin Immunol 2004, 16:321-327.

23. Watts TH: TNF/TNFR family members in costimulation of $T$ cell responses. Annu Rev Immunol 2005, 23:23-68.

24. Kober J, Leitner J, Klauser C, Woitek R, Majdic O, Stockl J, Herndler-Brandstetter D, Grubeck-Loebenstein B, Reipert BM, PickI WF, et al: The capacity of the TNF family members 4-1BBL, OX40L, CD70, GITRL, CD30L and LIGHT to costimulate human T cells. Eur J Immunol 2008, 38:2678-2688.

25. Curtsinger JM, Lins DC, Mescher MF: Signal 3 determines tolerance versus full activation of naive CD8 T cells: dissociating proliferation and development of effector function. J Exp Med 2003, 197:1141-1151.

26. Mescher MF, Curtsinger JM, Agarwal P, Casey KA, Gerner M, Hammerbeck $C D$, Popescu F, Xiao Z: Signals required for programming effector and memory development by CD8+ T cells. Immunol Rev 2006, 211:81-92.

27. al-Shamkhani A, Birkeland ML, Puklavec M, Brown MH, James W, Barclay AN: OX40 is differentially expressed on activated rat and mouse T cells and is the sole receptor for the OX40 ligand. Eur J Immunol 1996, 26:1695-1699.

28. Garber K: Beyond ipilimumab: new approaches target the immunological synapse. J Natl Cancer Inst 2011, 103:1079-1082.

29. Waller EC, McKinney N, Hicks R, Carmichael AJ, Sissons JG, Wills MR: Differential costimulation through CD137 (4-1BB) restores proliferation of human virus-specific "effector memory" (CD28(-) CD45RA(HI)) CD8(+) T cells. Blood 2007, 110:4360-4366.

30. Habib-Agahi M, Jaberipour M, Searle PF: 4-1BBL costimulation retrieves CD28 expression in activated T cells. Cell Immunol 2009, 256:39-46.

31. Curran MA, Kim M, Montalvo W, Al-Shamkhani A, Allison JP: Combination CTLA-4 blockade and 4-1BB activation enhances tumor rejection by increasing T-cell infiltration, proliferation, and cytokine production. PLoS One 2011, 6:e19499.

32. Pan PY, Zang Y, Weber $\mathrm{K}$, Meseck ML, Chen SH: OX40 ligation enhances primary and memory cytotoxic T lymphocyte responses in an immunotherapy for hepatic colon metastases. Mol Ther 2002, 6:528-536.

33. Melero I, Shuford WW, Newby SA, Aruffo A, Ledbetter JA, Hellstrom KE, Mittler RS, Chen L: Monoclonal antibodies against the 4-1BB T-cell activation molecule eradicate established tumors. Nat Med 1997, 3:682-685. 
34. Murata S, Ladle BH, Kim PS, Lutz ER, Wolpoe ME, Ivie SE, Smith HM, Armstrong TD, Emens LA, Jaffee EM, Reilly RT: OX40 costimulation synergizes with GM-CSF whole-cell vaccination to overcome established CD8+ T cell tolerance to an endogenous tumor antigen. J Immunol 2006, 176:974-983.

35. Vire B, de Walque S, Restouin A, Olive D, Van Lint C, Collette Y: Antileukemia activity of MS-275 histone deacetylase inhibitor implicates 4-1BBL/4-1BB immunomodulatory functions. PLoS One 2009, 4:e7085.

36. Buglio D, Khaskhely NM, Voo KS, Martinez-Valdez H, Liu YJ, Younes A: HDAC11 plays an essential role in regulating OX40 ligand expression in Hodgkin lymphoma. Blood 2011, 117:2910-2917.

37. Han Y, Wang Y, Xu HT, Yang LH, Wei Q, Liu Y, Zhang Y, Zhao Y, Dai SD, Miao Y, et al: X-radiation induces non-small-cell lung cancer apoptosis by upregulation of Axin expression. Int J Radiat Oncol Biol Phys 2009, 75:518-526.

38. Gal-Yam EN, Saito Y, Egger G, Jones PA: Cancer epigenetics: modifications, screening, and therapy. Annu Rev Med 2008, 59:267-280.

39. Cheng YW, Pincas H, Bacolod MD, Schemmann G, Giardina SF, Huang J, Barral S, Idrees K, Khan SA, Zeng Z, et al: CpG island methylator phenotype associates with low-degree chromosomal abnormalities in colorectal cancer. Clin Cancer Res 2008, 14:6005-6013.

40. Kouzarides T: Chromatin modifications and their function. Cell 2007 , 128:693-705.

41. Roth SY, Denu JM, Allis CD: Histone acetyltransferases. Annu Rev Biochem 2001, 70:81-120.

42. Seo SB, McNamara P, Heo S, Turner A, Lane WS, Chakravarti D: Regulation of histone acetylation and transcription by INHAT, a human cellular complex containing the set oncoprotein. Cell 2001, 104:119-130.

43. Eberharter A, Becker PB: Histone acetylation: a switch between repressive and permissive chromatin. Second in review series on chromatin dynamics. EMBO Rep 2002, 3:224-229.

44. Richon VM, Sandhoff TW, Rifkind RA, Marks PA: Histone deacetylase inhibitor selectively induces p21WAF1 expression and gene-associated histone acetylation. Proc Natl Acad Sci USA 2000, 97:10014-10019.

45. Dion MF, Altschuler SJ, Wu LF, Rando OJ: Genomic characterization reveals a simple histone $\mathrm{H} 4$ acetylation code. Proc Natl Acad Sci USA 2005 102:5501-5506.

46. Choudhary C, Kumar C, Gnad F, Nielsen ML, Rehman M, Walther TC, Olsen $J V$, Mann M: Lysine acetylation targets protein complexes and co-regulates major cellular functions. Science 2009, 325:834-840.

47. Kadosh D, Struhl K: Repression by Ume6 involves recruitment of a complex containing Sin3 corepressor and Rpd3 histone deacetylase to target promoters. Cell 1997, 89:365-371.

48. Wang Z, Zang C, Cui K, Schones DE, Barski A, Peng W, Zhao K: Genomewide mapping of HATs and HDACs reveals distinct functions in active and inactive genes. Cell 2009, 138:1019-1031.

49. Glozak MA, Seto E: Histone deacetylases and cancer. Oncogene 2007 26:5420-5432

50. Barneda-Zahonero B, Parra M: Histone deacetylases and cancer. Mol Oncol 2012, 6:579-589.

51. Marks P, Rifkind RA, Richon VM, Breslow R, Miller T, Kelly WK: Histone deacetylases and cancer: causes and therapies. Nat Rev Cancer 2001, 1:194-202.

52. Wang $\mathrm{H}$, Gao X, Yang JJ, Liu ZR: Interaction between p68 RNA helicase and Ca2+-calmodulin promotes cell migration and metastasis. Nat Commun 2013, 4:1354.

53. Livak KJ, Schmittgen TD: Analysis of relative gene expression data using real-time quantitative PCR and the 2(-Delta Delta C(T)) Method. Methods 2001, 25:402-408.

54. Ali MW, Cacan E, Liu Y, Pierce JY, Creasman WT, Murph MM, Govindarajan R, Eblen ST, Greer SF, Hooks SB: Transcriptional suppression, DNA methylation, and histone deacetylation of the regulator of G-protein signaling 10 (RGS10) gene in ovarian cancer cells. PLoS One 2013, 8:e60185.

55. Tsang KY, Zaremba S, Nieroda CA, Zhu MZ, Hamilton JM, Schlom J: Generation of human cytotoxic T cells specific for human carcinoembryonic antigen epitopes from patients immunized with recombinant vaccinia-CEA vaccine. J Natl Cancer Inst 1995, 87:982-990

56. Tsang KY, Zhu M, Nieroda CA, Correale P, Zaremba S, Hamilton JM, Cole D, Lam C, Schlom J: Phenotypic stability of a cytotoxic T-cell line directed against an immunodominant epitope of human carcinoembryonic antigen. Clin Cancer Res 1997, 3:2439-2449.
57. Liang G, Gonzales FA, Jones PA, Orntoft TF, Thykjaer T: Analysis of gene induction in human fibroblasts and bladder cancer cells exposed to the methylation inhibitor 5-aza-2'-deoxycytidine. Cancer Res 2002, 62:961-966

58. Dubovsky JA, McNeel DG, Powers JJ, Gordon J, Sotomayor EM, Pinilla-lbarz JA: Treatment of chronic lymphocytic leukemia with a hypomethylating agent induces expression of NXF2, an immunogenic cancer testis antigen. Clin Cancer Res 2009, 15:3406-3415.

59. Kane MF, Loda M, Gaida GM, Lipman J, Mishra R, Goldman H, Jessup JM, Kolodner R: Methylation of the hMLH1 promoter correlates with lack of expression of hMLH1 in sporadic colon tumors and mismatch repairdefective human tumor cell lines. Cancer Res 1997, 57:808-811.

60. Maeda T, Towatari M, Kosugi H, Saito H: Up-regulation of costimulatory/ adhesion molecules by histone deacetylase inhibitors in acute myeloid leukemia cells. Blood 2000, 96:3847-3856.

61. Zaks TZ, Chappell DB, Rosenberg SA, Restifo NP: Fas-mediated suicide of tumor-reactive T cells following activation by specific tumor: selective rescue by caspase inhibition. J Immunol 1999, 162:3273-3279.

62. Prado-Garcia H, Romero-Garcia S, Morales-Fuentes J, Aguilar-Cazares D, Lopez-Gonzalez JS: Activation-induced cell death of memory CD8+ T cells from pleural effusion of lung cancer patients is mediated by the type II Fas-induced apoptotic pathway. Cancer Immunol Immunother 2012, 61:1065-1080.

63. Chiou SH, Sheu BC, Chang WC, Huang SC, Hong-Nerng H: Current concepts of tumor-infiltrating lymphocytes in human malignancies. J Reprod Immunol 2005, 67:35-50.

64. Zola H: Markers of cell lineage, differentiation and activation. J Biol Regul Homeost Agents 2000, 14:218-219.

65. Tesniere A, Panaretakis T, Kepp O, Apetoh L, Ghiringhelli F, Zitvogel L, Kroemer G: Molecular characteristics of immunogenic cancer cell death. Cell Death Differ 2008, 15:3-12.

66. Hodge JW, Garnett CT, Farsaci B, Palena C, Tsang KY, Ferrone S, Gameiro SR: Chemotherapy-induced immunogenic modulation of tumor cells enhances killing by cytotoxic T lymphocytes and is distinct from immunogenic cell death. Int J Cancer 2013, 133(3):624-636. 10.1002/ijc.28070.

67. Feinberg AP, Vogelstein B: Hypomethylation distinguishes genes of some human cancers from their normal counterparts. Nature 1983, 301:89-92.

68. Rhee I, Bachman KE, Park BH, Jair KW, Yen RW, Schuebel KE, Cui H, Feinberg AP, Lengauer C, Kinzler KW, et al: DNMT1 and DNMT3b cooperate to silence genes in human cancer cells. Nature 2002, 416:552-556.

69. Sutheesophon K, Nishimura N, Kobayashi Y, Furukawa Y, Kawano M, Itoh K, Kano Y, Ishii H: Involvement of the tumor necrosis factor (TNF)/TNF receptor system in leukemic cell apoptosis induced by histone deacetylase inhibitor depsipeptide (FK228). J Cell Physiol 2005, 203:387-397.

70. Earel JK Jr, VanOosten RL, Griffith TS: Histone deacetylase inhibitors modulate the sensitivity of tumor necrosis factor-related apoptosis-inducing ligandresistant bladder tumor cells. Cancer Res 2006, 66:499-507.

71. Fornace AJ Jr, Amundson SA, Do KT, Meltzer P, Trent J, Bittner M: Stressgene induction by low-dose gamma irradiation. Mil Med 2002, 167:13-15.

72. Woloschak GE, Paunesku T: Mechanisms of radiation-induced gene responses. Stem Cells 1997, 15(Suppl 2):15-25.

73. Chen M, Quintans J, Fuks Z, Thompson C, Kufe DW, Weichselbaum RR: Suppression of $\mathrm{BCl}-2$ messenger RNA production may mediate apoptosis after ionizing radiation, tumor necrosis factor alpha, and ceramide. Cancer Res 1995, 55:991-994

74. Ropero S, Esteller M: The role of histone deacetylases (HDACs) in human cancer. Mol Oncol 2007, 1:19-25.

75. Sharma NL, Groselj B, Hamdy FC, Kiltie AE: The emerging role of histone deacetylase (HDAC) inhibitors in urological cancers. BJU Int 2013, 111:537-542.

76. Redner RL, Wang J, Liu JM: Chromatin remodeling and leukemia: new therapeutic paradigms. Blood 1999, 94:417-428.

77. Saunders N, Dicker A, Popa C, Jones S, Dahler A: Histone deacetylase inhibitors as potential anti-skin cancer agents. Cancer Res 1999, 59:399-404.

78. Yoshida M, Horinouchi S: Trichostatin and leptomycin. Inhibition of histone deacetylation and signal-dependent nuclear export. Ann N Y Acad Sci 1999, 886:23-36.

79. Kosugi H, Towatari M, Hatano S, Kitamura K, Kiyoi H, Kinoshita T, Tanimoto M, Murate T, Kawashima K, Saito H, Naoe T: Histone deacetylase inhibitors are the potent inducer/enhancer of differentiation in acute myeloid 
leukemia: a new approach to anti-leukemia therapy. Leukemia 1999,

13:1316-1324.

80. Rajgolikar G, Chan KK, Wang HC: Effects of a novel antitumor

depsipeptide, FR901228, on human breast cancer cells. Breast Cancer Res

Treat 1998, 51:29-38.

81. Weinberg AD, Morris NP, Kovacsovics-Bankowski M, Urba WJ, Curti BD: Science gone translational: the OX40 agonist story. Immunol Rev 2011, 244:218-231.

doi:10.1186/2051-1426-1-17

Cite this article as: Kumari et al.: Turning T cells on: epigenetically enhanced expression of effector T-cell costimulatory molecules on irradiated human tumor cells. Journal for ImmunoTherapy of Cancer 2013 1:17.

\section{Submit your next manuscript to BioMed Central and take full advantage of:}

- Convenient online submission

- Thorough peer review

- No space constraints or color figure charges

- Immediate publication on acceptance

- Inclusion in PubMed, CAS, Scopus and Google Scholar

- Research which is freely available for redistribution 